\title{
The Difficult Course of the Heavy Enterprise in the Reform of China's State-owned Enterprises
}

\author{
Zixuan Luo \\ Business School, University of International Business and Economics, Beijing, 100029, China
}

Keywords: Reform of state-owned enterprise, Enterprise structure, Ansteel, Kailuan Mines

\begin{abstract}
In the view of the reform of China's state-owned enterprise, the supply-side structural reform and overcapacity-reduction have become the key words for the reform. The paper first discusses achievements and lessons obtained at different stages by the reform of China's state-owned enterprise and analyzes the trend for the reform of China's stated-owned enterprise in new reality and environment. Then, the achievement of Ansteel in the reform is analyzed as an example along with its enterprise structure, main business and the change of its overall strength to summarize the reason why Ansteel get out the dilemma in the aspect of history and its effort. Next, the paper also analyzes the case that one enterprise remains in the dilemma of loss because of its unchanged action in the reform with Kailuan Mines as an example and the reason why Kailuan Mines lost its advantages in the aspects above. Finally, the paper also discusses the development direction and the issues which should be attached with importance as they deserved by Ansteel and Kailuan Mines in the recent situation.
\end{abstract}

\section{The Changing Stages for the State-owned Enterprises}

In the start of the reform of China's state-owned enterprises in the year of 1978, it tends to solve the problem of inflexible system, integration of government administration with enterprise, loss of autonomous right and the severe loss of assets. To encourage the staff and the enterprise, the government has carried out many policies to help the state-owned enterprise adapt to the market economy. To meet the demand in the economy situation, it is necessary to govern and reform the stat-owned enterprises for a further step and reduce overcapacity and improve the structure at the same time according to the new requirement for modern enterprise structure. The paper discussed the process and achievement of China's enterprise reform in the case of Ansteel and Kailuan Mines.

\section{Features and Problems of China's State-owned Enterprise Reform}

The state-owned enterprise reform is concentrated how to turn state-owned enterprises into standard modern enterprises and make it fair for them in the aspect of management and competition in market economy. During the reform. Both environment and related policies has been adopted. There is also lots of practice and study on the structure and management in state-owned enterprises to put forward further suggestion for reform in the economy situation at that time. The reform intends to solve the structural problem that they always occupy the key position in industrial chain, output the raw material and large-scale project and control both light and heavy industry and other industries in energy, information, finance and so on. There will be a terrible waste if the structure in state-owned enterprises is messy or it is ineffective in schedule and stall management.

\section{Main Achievements and Lessons of the Reform of State-owned Enterprise}

\subsection{Achievements}

The success of the reform of state-owned Enterprise is determined by two factors: the complete policies and the cooperation from the enterprise. For the policies, the government has kept carrying out related policies and enforced it to push forward the reform. The policies of the reform of the state-owned enterprises does not only include the reconstruction of the enterprise and change of the 
service, it also includes the placement of staff, the medium and small enterprises in local area and the fairness among private enterprises. The complete policy system not only ensure the management of the reform of state-owned enterprises legally, it also keeps away the loss and damage to economy, which lay the foundation for a better economy environment. For the cooperation from enterprises, many of them cooperate with the policies actively. Not only the managers of the enterprise take part in finding a new way, the staff on the firing line, related enterprises and brother enterprises make contribution to pushing forward the reform, helping large enterprises to complete the industrial integration and diversified operation and improving the inner management. In the new era, the enterprise does no only obey the policies or try to service, it also pursues higher development and interest, which can be regarded as one turning point of state-owned enterprises from national machine to modern enterprise.

\subsection{Lessons during the State-Owned Reform Period}

There are two main factors for the failure in the reform of the state-owned enterprises-low efficiency and dilemma for exceptions. The low efficiency and management refers to the large amount of time and human resource into the same work in the reform of the stat-owned enterprises. It is a typical issue that need to be solved quickly. Besides, there are many exceptions in the state-owned enterprises. These exceptions, ranging from tiny ones to large ones, are hard to handle because of the lack of experience. To find a solution, only long-term exploration and study can do. Any improper action can cause more problems.

\section{Successful Experience in the Reform of State-Owned Enterprises in Angang Group}

\subsection{Changes in the Structure of Enterprises}

In 1948, Anshan Iron \& Steel Company was established, followed by Anshan Iron and Steel works after liberation. Anshan Iron \& Steel Co., Ltd. (listed in Shenzhen and Hong Kong) was established mainly through state-owned companies. The SASAC has changed its name to Anshan Iron \& Steel Group Co., Ltd. And now the State-owned Assets Supervision and Administration Commission of the State Council holds 100\% of the shares of Anshan Iron \& Steel Group Company.

\subsection{Main Business and Changes of the Enterprise}

Angang was originally established mainly to produce steel, iron and military materials, and later gradually expanded to produce a variety of raw materials and steel for specific needs, mining mines. During the period 1974-1999, in addition to the original business, Angang also carried out special steel and mining equipment research and development. Since 21th century, the business of Anshan Iron \& Steel Co., Ltd has been diversified, including the comprehensive utilization of vanadium and titanium resources, the development of non-steel sectors such as finance, trade, engineering technology, information industry, integrated industry, chemical industry, etc. The main business from pure steel production to special steel manufacturing, equipment and related technology research and development.

\subsection{Brief Introduction of Angang Reform}

Angang's Main Financial Indicators in the Near Future.

Angang Reform Angang has always been a more active element in the process of SOE reform, and has always been in the forefront of SOEs in the reorganization and restructuring of the group, so its ability to adapt to the changes in the economic situation is also relatively strong.It is worth noting that although Anshan Iron and Steel failed to completely eliminate the shortcomings of the previous period in every reform, it was able to make up for these loopholes in the continuous improvement of the latter period. For example, public and private management problems and financial difficulties caused by sustained losses are often a problem of procrastination when other SOEs reform. Generally speaking, Angang is a relatively successful example in the process of SOE reform, but its success in reform does not represent its overall success in management. Anshan Iron and Steel has just turned losses into profits. Under the situation of the completion of the corporate system reform, it is 
necessary to stimulate their own vitality, promote the economic development of the region, realize the diversified management path, and make contributions to the economic development of the country as a successful enterprise.

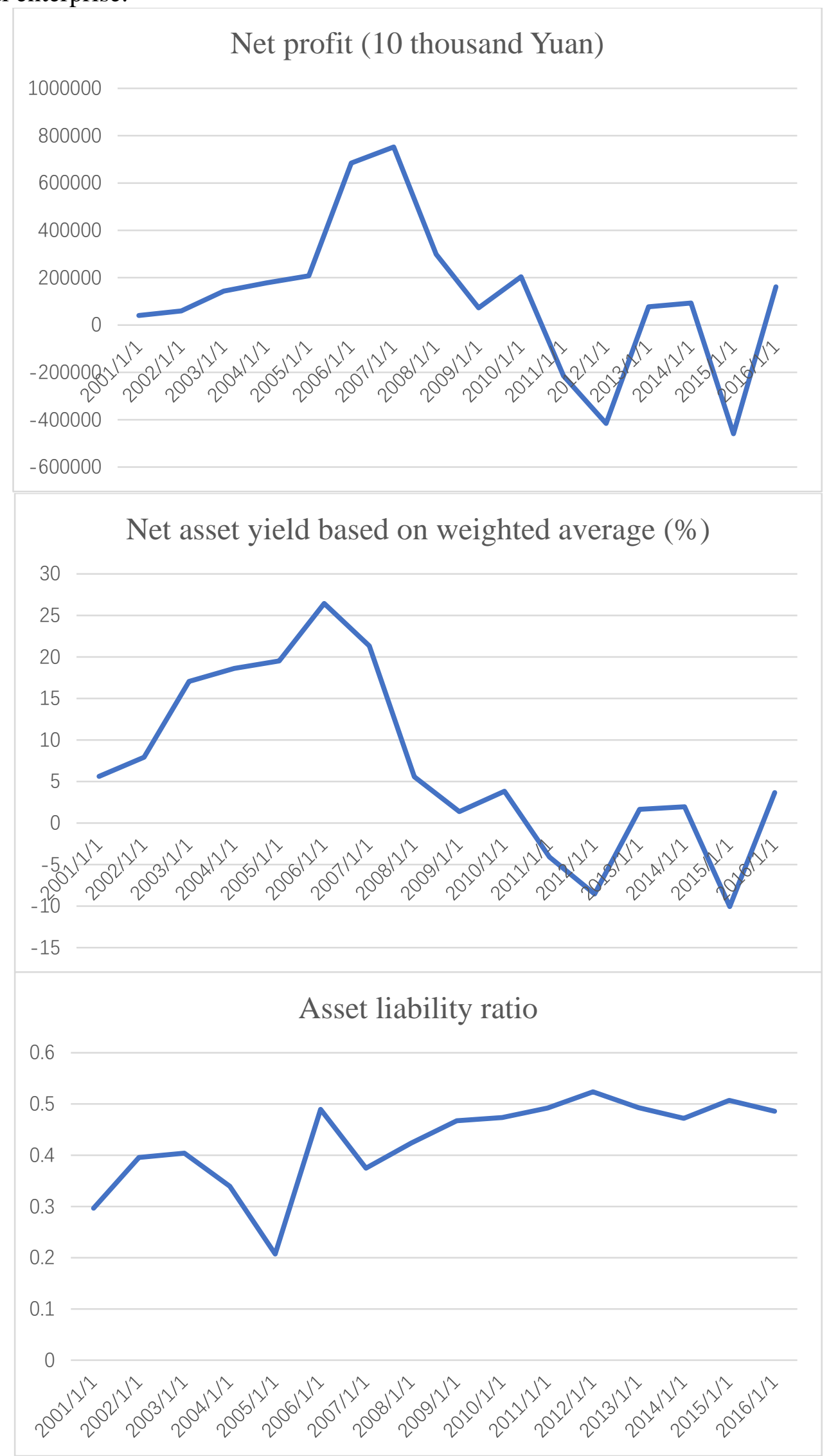

Figure 1. Angang's Main Financial Indicators in the Near Future 


\section{Failure Lessons of Kailuan Coal Mine in Reform}

Changes in the Structure of Enterprises. Since the Kailuan coal mine was opened with the help of the Qing government at the end of 18th century, the Kailuan coal mine has experienced the control of Japan and the British side successively, and has operated under the Kuomintang government for a period of time. Its management power and ownership have been unclear. After liberation, nationalization was carried out until the system was reformed in 1999. During this period are relatively stable and good production and operation, but after 2000 , the company's performance is not satisfactory.

Main Business and Changes of The Enterprise.

Brief Introduction of Kailuan Coal Mine Reform.

Financial indicators of Kailuan Coal Mine in the Near Future.

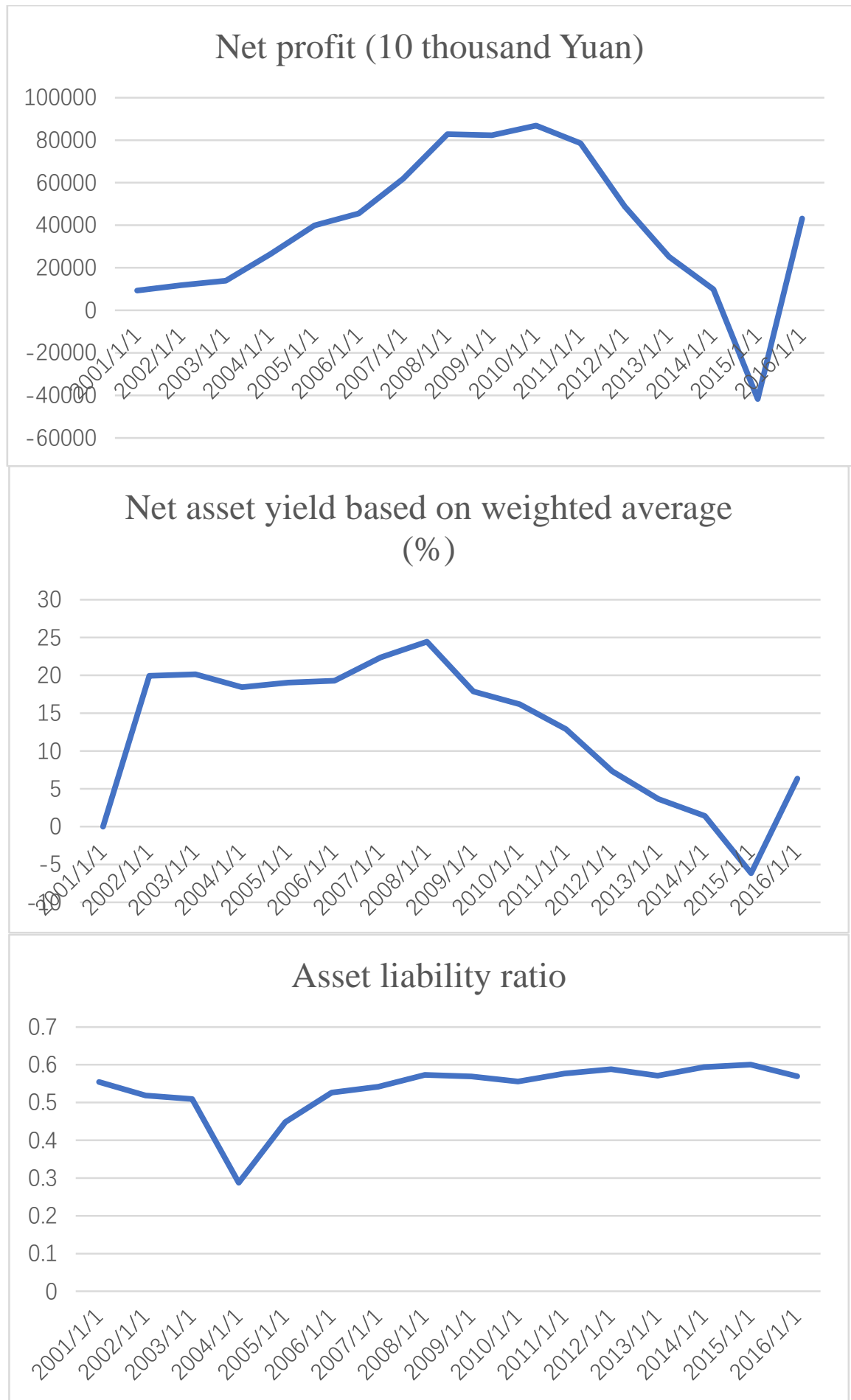

Figure 2. Financial indicators of Kailuan Coal Mine in the Near Future 
Kailuan Reform. On the basis of ensuring the normal operation of its main business, now Kailuan Group further expand to the logistics industry and coal mine culture park, so as to absorb and transform excess production capacity, at the same time, stimulate regional economic growth, improve the economic structure; These current reform measures are undoubtedly correct and reasonable, but under the premise of large liabilities and large number of fixed assets and intangible assets, it is still necessary to examine whether the company can operate well or not.In addition, the appointment and removal of employees in Kailuan Coal Mine will directly affect many families living in the area, thus affecting the local social stability and economic stability;And will be in the early stage of the pollution of the environment is not enough scientific exploitation and refining waste and influence on the geological structure of the long-term existence and continued to plague the group's production and people's normal life, this is common in early large state-owned enterprises in Kailuan is difficult to be solved, the need for government and enterprise long-term cooperation to improve the receiving effect.

\section{References}

[1] Wang Yong. The Inner Logic Between State-owned Enterprise Reform and Management Innovation [J]. Commercial Research, 2012(12): 76-82.

[2] Xing Wei, Zhou Xiao. Reform of State-Owned Enterprises and the Transformation of Technological Innovation Pattern [J]. Industrial Economics Research, 2016(6): 22-33+45.

[3] Xu Zhaoyuan, Zhang Wenkui. SOEs Reform's Impact on Economic Growth [J]. Economic Research Journal, 2015,50(04):122-135.

[4] Yang Weidong. The Reviews of a New Round of Reform of State-owned Enterprise [J]. Journal of Huazhong Normal University (Humanities and Social Sciences), 2014, 53(3): 29-43.

[5] Yang Weidong. Reflection on the State-owned Enterprise Reform and Re-nationalization [J]. Journal of Huazhong Normal University (Humanities and Social Sciences), 2013, 52(1): 23-37.

[6] Sheng Feng. Productive and Innovative Efficiency in State- owned Enterprises Reform: Based on China's Manufacturing Firm-level Data Analysis [J]. Industrial Economics Research, 2012(04): 37-46. 